\title{
Eine bessere Welt
}

\section{Erhard Taverna}

Dr. med., Mitglied der Redaktion

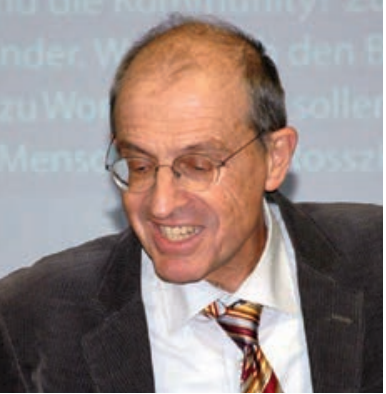

Andreas Köhler
Schlaraffenländer, Mythen vom kollektiven Glück, Verheissungen, Gegenwelten und Utopien. Seit 2004 doziert Andreas Köhler in jedem Herbstsemester an der Universität St.Gallen. "Wissen schafft Wirkung» steht auf dem Verzeichnis öffentlicher Vorlesungen mit einer breiten Palette an Themen. Was der Psychiater und Romanautor jährlich anbietet, ist auch als Veranstaltung zur Weiterbildung für die Fachleute seines Berufes anerkannt. Der Präsident der St. Galler Gesellschaft für Psychiatrie und Psychotherapie SGGPP ist überzeugt, dass sich Therapeuten mit historischen und gegenwärtigen Wunsch- und Horrorvisionen auseinandersetzen sollen: «Der Psychiater aber, der Seelenmediziner, beschäftigt sich mit Körper und Seele des Menschen. Dieser lebt allerdings in einer Gesellschaft. Und so soll sich der Arzt auch mit den Vorstellungen und Bildern, die sich Menschen von dieser Gesellschaft machen, und mit deren Hoffnungen auseinandersetzen.» Auf Themen wie «Was ist die Seele?», Melancholie, Angst, Askese und Rausch, Schreckensvisionen und magisches Denken folgten die grossen Erzählungen zu Ursprungsmythen und Jenseitsvorstellungen. Mit «Massenglück und Tyrannei» ist die vorläufig letzte Vorlesungsreihe im Dezember 2016 zu Ende gegangen. Die berühmte Begegnung des Grossinquisitors mit Christus aus dem Roman Die Brüder Karamasow von Dostojewskij war das wiederkehrende Leitmotiv. Von Augustin über Hobbes und Rousseau zu Comte, Marx und Wells, von Proudhon und Samjatin zu Orwell und Huxley und weiteren Autoren, entfaltete die Zeitreise ein Panorama menschlicher Sehnsüchte und Untergangsvisionen. Das Ideal des wohlorganisierten Glücks war stets auch eine Kritik an den bestehenden Verhältnissen. Wo die Sicherheit höher als die Freiheit gewichtet wird, geht, wie alle Beispiele zeigen, beides verloren. Die Mär von Sebastian Brants Narrenschiff, aus einer weiteren Vorlesungsreihe, kann man auch als Parodie auf die seit Platon häufigen Entwürfe asketischer Tugendstaaten lesen. Wer Unmögliches erstrebt, nimmt Kurs auf Narragonien, statt auf Inseln wie Utopia oder Neu-Atlantis zu landen. Menschen sind Narren auf ihrer Lebensreise, dauernd in Gefahr, Schiffbruch zu erleiden. Von der technischen Euphorie des 19. Jahrhunderts ist seit Jules Verne nicht viel übrig geblie- ben. Es überwiegen die Unheilsgeschichten und Weltuntergänge, Dystopien von Wells' Krieg der Welten bis zu den Hunger Games von Suzanne Collins oder Dmitry Glukhovskys Metro 2033-Trilogie.

Biologie, Geschichte und Philosophie sind für den naturwissenschaftlich interessierten Psychiater und Psychotherapeuten die Grundlagen seiner beruflichen Arbeit. Nach dem Staatsexamen 1975 in Zürich dissertierte er mit seiner Arbeit Religiöser Wahn und Religiosität. Ausser an der Uni liest er auch regelmässig im Café St Gall der Bibliothek Hauptpost aus eigenen Werken oder ausgewählten Büchern. Im Januar 2017 aus Zenos Gewissen von Italo Svevo, im April aus Charles Darwins Der Ausdruck der Gemütsbewegung bei dem Menschen und den Tieren. Köhler ist ein rhetorisch geschulter Vorleser mit einer geschliffenen Sprache und einer lebhaften Mimik und Gestik, die keine Langeweile aufkommen lässt.

Vor allem die Medienmacht Berlusconis brachte ihn auf die Idee, mit einer Sammlung fiktiver Blogbeiträge (www.rosszko.com) den Einfluss der Informationsträger collageartig vorzuführen. Stimmen, die von sich erzählen und, wie bei Thomas Hobbes' Titelbild der Erstausgabe, einen Leviathan formen. Ein Metagebilde, einen Staat, eine Kolonie, bildlich aus unzähligen Individuen aufgebaut. Nach jeder Vorlesung bekamen die Besucher Textproben aus dem Projekt zu hören, das möglicherweise am Anfang einer neuen Buchidee steht. Für jeden Vortragszyklus gab es ein perfektes, reich bebildertes Skript zu lesen. Fotos, Grafiken, Bildmontagen, Websites, Buchumschläge und das Layout zum Druck entstehen auf dem eigenen Computer des vielseitigen Autors, der früher, nach Kursen an der Kunstgewerbeschule, auch gemalt hat.

Andreas Köhler ist in vielen Gattungen souverän zu Hause. Er weiss, dass erst aus persönlich erlittenen Lebensgeschichten entsteht, was wir abstrakt Geschichte nennen. Wir sind, weil wir erzählen.

\section{Bildnachweis}

Foto Erhard Taverna

www.andreas-koehler.com

www.rosszko.com 